\title{
READING THEORIES AND READING COMPREHENSION
}

\author{
Maria Novary Ngabut \\ Universitas Palangkaraya \\ mary.ngabut@gmail.com
}

\begin{abstract}
In this article several reading theories in their relations to reading comprehension teachers and lecturers of English need to know are reviewed. At the theory level, three other Models of Reading, namely Bottom-Up, Top-Down, and Interactive are previously discussed to the Schema Theory. In reviewing the reading comprehension, the history of reading instruction, types and purposes of reading, and cognitive reading skills are discussed. Finally, it reviews six variables involved in the comprehension of English texts.
\end{abstract}

Keywords: models of reading, schema theory, comprehension, background knowledge

This article is a review of reading theories and reading comprehension discussed in a wide range of books, journals, articles, and the like. Here four main topics are reviewed, namely (i) the nature of reading, (ii) schema theory, (iii) reading comprehension, and (iv) the variables involved in comprehension.

\section{NATURE OF READING}

Reading is an extremely complex process that no one can explain satisfactorily. Those who are interested in reading have their fundamental diverse views which resul from two different schools of psychology: behaviourism and cognitivism. In relation to these, most models of reading are partial in that they are concerned with specific aspects (for example, perceptual or cognitive), stages (beginning or skilled reading), or modes (oral or silent reading). They do not attempt to account for all aspects of the reading process. There has been no single model that can be called the most acceptable.
The models can be placed in one of the three categories: bottom-up, topdown, and interactive (Harris \& Sipay, 1984:6). A discussion of the three models now follows.

\section{Bottom-up Models}

Bottom-up models ot the reading process view reading as basically a translating, decoding, or encoding process. Here the reader starts with letters or larger units, and as he attends to them he begins to anticipate the words they spell. When the words are identified, they are decoded to inner speech from which the reader derives meaning in the same way as listening. In this process reading comprehension is believed to be an automatic outcome of accurate word recognition.

The followers of these models have argued that reading is essentially the translation of graphic symbols into an approximation of oral language. These models are influenced by behaviourist psychology and thus structural linguistics 
in which they are mostly appropriate for beginning readers.

\section{Top-down Models}

In top-down models of reading, the reader's cognitive and language competence plays a key role in the construction of meaning from printed materials. Most of these models (Goodman, 1967; Smith, 1971) are based on psycholinguistic theory, that is, the theory in which there is an interaction between thought and language. Goodman (1967) defines reading as a process which involves using available language cues that are selected from perceptual input on the basis of reader's predictions. As the information is processed, tentative decisions about meaning are confirmed, rejected, or refined as the reading progresses. Graphic information in the top-down models is used only to support or reject hypotheses about meaning.

$$
\text { Meaning, in this case }
$$
comprehension, according to these models is obtained by using only as much information as necessary from the graphic, syntactic, and semantic cue systems. Other cues are based upon the reader's linguistic competence. In contrast to reading as translation models, that is, the bottom-up ones, top-down models theorists believed that skilled readers go directly from print to meaning without first reading to speech (Harris \& Sipay, 1984).

These models are influenced by psycholinguists, and they are mostly appropriate for skilled readers at the level of advanced or more advanced.

\section{Interactive Models}

Theoriests on interactive models such as Rumelhart (1980) believe that, at least for skilled or advanced readers, topdown and bottom-up processing in reading seem to occur simultaneously. Rumelhart believes that comprehension is dependent on both graphic information and the information in the reader's mind. Comprehension, therefore, may be obstructed when a critical skill or a piece of knowledge is missing. In a case such as this, the skilled reader compensates by decoding a word, relying on context, or both word and context.

In conjunction with these theories, reading is defined as the meaningful interpretation of printed or written symbols, while comprehending is a result of the interaction between the perception of graphic symbols that represent language and the reader's language skill, and his knowledge of the world. In this process the reader tries to create meanings that are intended by the writer (Harris \& Sipay, 1984:8).

Therefore, the nature of reading task changes as the learners progress from less mature to more mature levels. Reading in this case is not one skill but a large number of interrelated skills that develop gradually over a period of years. So, it is a complex process in which the recognition and comprehension of written symbols are influenced by reader's perceptual skills, decoding skills, experiences, language backgrounds, mind sets, and reasoning abilities.

This last model will be discussed further as this model has become the centre of interest for recent theories, research, and practice in teaching reading. The discussion will be covered in schema theory. 


\section{SCHEMA THEORY}

The notion of schema and related concepts results from the development of research in cognitive science where the importance of background knowledge in language comprehension is found to exist. Rumelhart (1980:34) points out that

A schema theory is basically a theory about knowledge. It is a theory about how knowledge is represented and about how that representation facilitates the use of knowledge in particular ways. According to schema theories, all knowledge is packaged into units. These units are the schemata. Embedded in these packages of knowledge is, in addition to the knowledge itself, information about how this knowledge is to be used. A schema, then, is a data structure for representing the generic concepts stored in memory.

In relation to the definition above, McCormick \& Pressley (1997:62-63) define schemata as generalised knowledge about objects, situation, and events. Activation of schema, according to them, can dramatically affect comprehension, inferences, attention allocation, and memory of what is read. The title of passage can also activate schemata.

Related to reading, according to schema theory, a text only provides directions for readers as to how they should retrieve or construct meaning from their own previously acquired knowledge. The previously acquired knowledge is called the reader's background knowledge, and its structures are called schemata (Rumelhart, 1980). Then, on the basis of this theory, comprehending a text is an interactive process between the reader's background knowledge and the text. Efficient comprehension, then requires the ability to relate the textual materials to one's own knowledge. Comprehending words, sentences, and entire texts involves more than just relying on one's linguistic knowledge (Carrell \& Eisterhold, 1988:76).

The process of interpretation is guided by the principle that every input is mapped against some existing schema and that all aspects of that schema must be compatible with the input information. This principle results in two basic modes of information processing: bottom-up and top-down. Bottom-up processing is evoked by the incoming data, while the features of data enter the system with the best fitting, bottom-up schemata. In this mode schemata are hierarchically organised, starting from the most general at the top to the most specific at the bottom. As these bottom-up schemata converge into higher level ones, they become activated. Therefore, bottom-up processing is called data-driven. Or in other words, the interpretation is from parts to whole.

Top-down processing, on the other hand, occurs as the system makes general predictions based on higher level, general schemata and then searches the input for information to fit into these partially satisfied, higher ordered schemata. Topdown processing is, therefore, called conceptually-driven processing.The process starts from whole to parts (Rumelhart, 1980; Carrell \& Eisterhold, 1988).

An important aspect of top-down and bottom-up processing is that both should be occurring at all levels simultaneously. The data needed to instantiate or fill out are available through 
bottom-up processing, while top-down processing facilitates their assimilation if they are anticipated by or consistent with the reader's conceptual expectations. Bottom-up processing ensures that readers will be sensitive to information that is novel or that does not fit their on going hypotheses about the content or structure of the text, while top-down processing helps the readers to resolve ambiguities or to select between alternative possible interpretations of the incoming data. Rumelhart (1980), furthermore, says that these two basic modes of information processing are used as sources of activation for schemata.

Schema-theoretic processes as discussed above all led to new, interactive models for reading. On the basis of
Rumelhart's proposal of the interactive processing, Lee \& VanPatten (1995:190-2) state that the model consists of several knowledge sources representing different levels of linguistic representation (feature, letter, letter cluster, lexical, and semantic knowledges) as shown in Figure 1. Interactive models of reading posit that the components of the model, the knowledge sources, all act simultaneously and in parallel on the incoming input.

Figure 1 shows that each knowledge source is connected to each of the others. Each can influence the others, either singly or in combination, so that semantic knowledge can aid feature analysis or syntactic knowledge can aid letter analysis. A very brief description of the elements of the model is as follows:

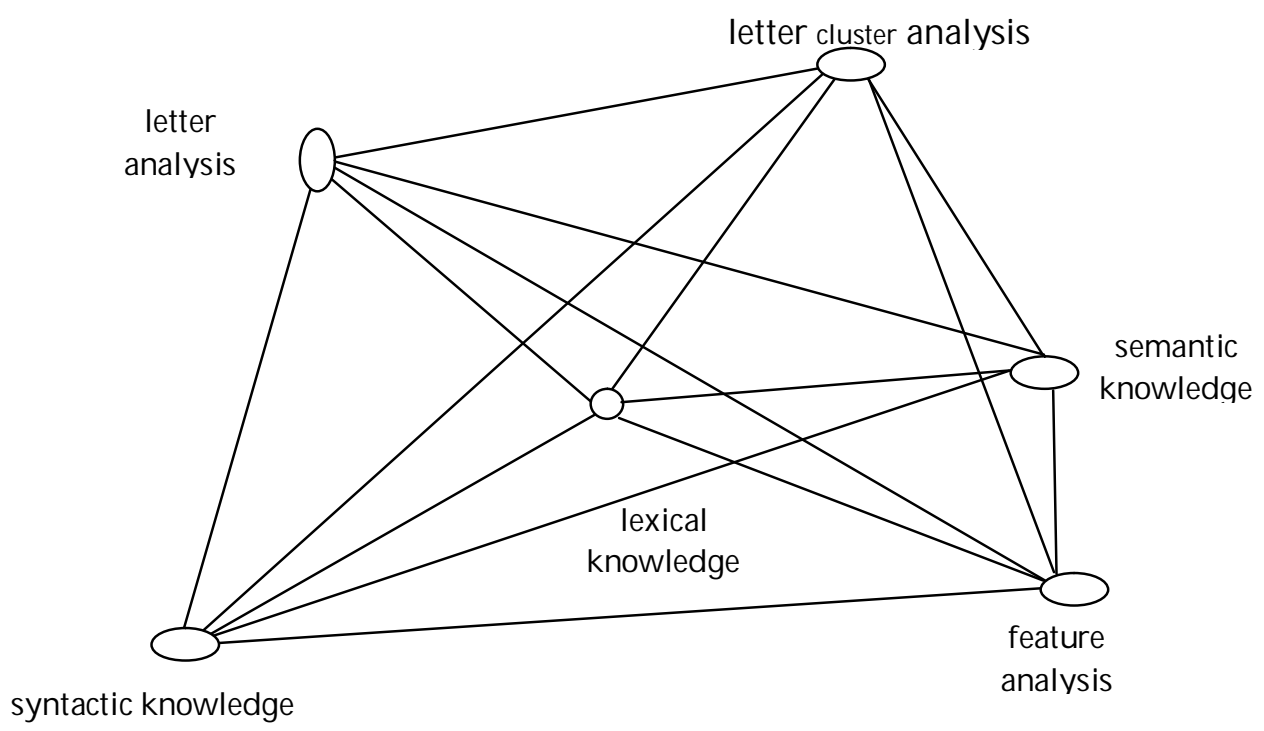

Figure 1. An Interactive of Model of Reading (Lee \& VaPatten, 1995:191)

Feature analysis refers to the act of recognising a loop in a letter and the direction of the loop $(p)$, whereas letter analysis is recognising that the loops make a specific letter $(p)$ versus $d$ versus $b$ ). Certain letters do and do not cluster in particular languages, and the clusters syllabify in particular way. Letter cluster analysis tells us that the letter th cluster in English as in the and ar-thri-tis. Syntactic knowledge identifies the order of words in a language so as to make a person is able to know the difference between 'Marko hit Yeti' and 'Yeti hit Marko'. This means that the same words ordered in different ways can produce different meanings. So, it is 
our syntactic knowledge that identifies the meaning in the order of the words. Lexical knowledge concerns individual word properties and meaning, so that the word work is identified as different from word and fork, though the last two words are only different from the first in one phoneme. Lastly, semantic knowledge governs meaning at all levels (word, phrases, clauses, sentences, and paragraphs).

According to interactive models of reading, comprehension is built up or constructed from knowledge sources which interact with each other on the input from the written page. Comprehension, then, is the process of relating new or incoming information to information which is already stored in the memory. Here, readers make connections between the new information on the printed page and their existing knowledge. They must allow the new information to enter and become a part of their knowledge store.

In short schema theory as a learning theory that asserts language comprehension involves an interactive process between the learner's background knowledge and the text. In an interactive processing, the reader uses top-down processing when he relates what he already knows to the text being processed, and uses bottom-up processing when he relates the text being processed to what he already knows.

\section{READING COMPREHENSION}

From the psycholinguistic point of view, reading is not primarily a visual process. There are two kinds of information involved in reading: (i) visual information, that is the one that comes from the printed page and (ii) non-visual information, that is, the information that comes from the brain of the reader. Visual information can be seen in a text or any form of writing, while non-verbal information is what the reader already knows about reading, about language, and about the world in general (Smith, 1973:6). This means that being able to see sentences in front of our eyes is not enough; we must know something of the language in which the material is written, about its subject matter, and about reading itself.

In relation to reading comprehension, four things are necessary to be reviewed, namely, (i) history of reading instruction, (ii) types and purposes of reading, (iii) cognitive reading skills, and (iv) variables involved in comprehension.

\section{History of Reading Instruction}

Silberstein (1987:28-33) discusses reading instruction as reflected during the twenty-five-year's publication of the journal English Teaching Form (1962 1987). She divides the reading instruction into three periods of development: (i) a decade of questioning (1962 - 1973), (ii) reading and psycholinguistics (the 1970s), and (iii) interactive reading (the 1980s). During the first period, there aws a substantial debate over the role of reading instruction in language classrooms, that is, on the utility of audiolingualism in which the written texts were used as grist for an oral mill. A major transformation in the conceptual model of reading had already begun with the publication of Goodman's (1967), article Reading: A Psycholinguistic Guessing Game. During the 1970s, the impact of this view on second language 
reading came to be seen, not only a a vehicle for language instruction, but also as a unique information-processing skill.

In the second period, psycholinguists like Goodman refuted the view of reading as essentially a mechanical decoding of speech written down. Psycholinguists advocated a very different model of thinking in regard to reading. A modern psycholinguistic perspective on reading, according to them, is based on insights derived from contemporary linguistics and cognitive psychology. From this perspective, reading is viewed as a complex information-processing skill in which the reader is seen as an active planning, decision-making individual who coordinates a number of skills and strategies to facilitate comprehension.

Goodman (1967) attacked previous views of reading by stating: "Simply stated the common sense notion I seek to refute here is this: Reading is a precise process. It involves exact, detailed, sequential perception and identification of letters, words, spelling patterns, and large language units". He then advocated the following new paradigm of reading:

In place of this misconception, I offer this; Reading is a selective process. It involves partial use of available minimal language cues selected from perceptual input on the basis of reader's expectation. As this partial information is processed, tentative decisions are made to be confirmed, rejected, or refined as reading progresses. More simply stated, reading is a psycholinguistic guessing game. It involves an interaction between thought and language. Efficient reading does not result from precise perception and identification of all elements, but from skill in selecting the fewest, most productive cues necessary to produce guesses which are right the first time.

In accordance with the psycholinguistic framework for reading, Silberstein (1987:31) is of the opinion that, initially, many psycholinguists assumed that only advanced readers could benefit from this approach to reading. Gradually, however, reading skills have appeared in beginning texts as well. It has become evident that successful reading at all levels entails the cognitive processes delineated above.

In the interactive reading period of the 1980s it emphasised that meaning is not fully present in a text waiting to be decoded. Rather, meaning is created through the interaction of text and reader. In this model of reading, background knowledge which facilitates text compehension has an important role to play. Here schema theory which has been discussed earlier comes into play. Interactive reading has come to refer to the interaction of top-down (conceptuallydriven) and bottom-up (data-driven) processing.

This model suggests that no text can be considered generically difficult or easy simply on the basis of linguistic features such as syntactic complexity or word frequency. Texts become easier if they correspond to students' prior knowledge of language, rhetorical conventions, and the world.

Reading activities developed within an interactive framework have placed particular emphasis on teaching students to activate and use their background knowledge. This emphasis is realised in what is called prereading activities, that is, the activities undertaken 
in order to build and activate their background knowledge. This approach seems to be more appropriate for developing students' reading skills as well as their reading proficiency (Dennis, McKena, and Miller, 1989; Omaggio, 1986; Clarke and Silberstein, 1979; Papalia, 1987; Carrell, 1987; McKay, 1987).

\section{Types and Purposes of Reading}

Types and purposes of reading cannot be separated from comprehension. Each type will determine what to achieve during or after reading. In conjunction with this Clarke and Silberstein (1979) point out that classroom activities should parallel the real world as closely as possible. Language is a tool of communication, so methods and materials should concentrate on the message, not on the medium. Then, the purposes of reading should be the same in class as they are in real life.

In general there are four types of reading, and thus four purposes of reading (Clarke and Siberstein, 1979; Greenwood, 1981; Grellet, 1987), although the writers have slightly diverse terminologies. They are (1) skimming (in order to obtain the general idea of the author), (2) scanning (in order to obtain specific fact or piece of information), (3) intensive or thorough reading (in order to obtain a comprehensive understanding of a reading text, in this case, reading for detail), and (4) critical reading (in order to evaluate information to determine where it fits into one's own system of beliefs). These types of reading can also be called reading strategies for obtaining necessary information and for determining the proper approaches for a reading task.
It is expected that knowing the types and purposes of reading and then applying the strategies will be very helpful for students to develop their reading skills.

\section{Cognitive Reading Skills}

Efficient reading depends first of all on having a purpose for reading. In this case, the reader knows why he is reading a text. One possible way of establishing a purpose of reading is by focussing the learner's attention on a particular cognitive skill. Many lists of cognitive skills have been suggested by those who are interested in reading instruction, but they all include most of the following (Greenwood, 1981: 89):

1. to anticipate both the form and the content;

2. to identify the main idea (s);

3. to recognise and recall specific details;

4. to recognise the relationship between the main idea(s) and its (their) expansion (example, lists, etc.);

5. to follow a sequence, such as events, illustration, stages of arguments;

6. to infer from the text (to read between the lines);

7. to draw conclusions; and

8. to recognise the writer's purpose and attitude.

In relation to the above reading skills, Brown in Mueller \& Tiffany (n.d.) has compiled a taxonomy of reading microskills. The taxonomy provides an overview of the skill processes learners must learn to perform as they become efficient readers. The following are the taxonomy of reading microskills: 
1. Discriminate among the distinctive graphemes and orthographic patterns of English.

2. Retain chunks of language of different lengths in short-term memory.

3. Process writing at an efficient rate of speed to suit the purpose.

4. Recognise a core of words, and interpret word order patterns and their significance.

5. Recognise grammatical word classes, verbs, etc), systems, (e.g. tense agreement, pluralisation), rules and elliptical forms.

6. Recognise that a particular meaning may be expressed in different grammatical forms.

7. Recognise cohesive devices in written discourse and their role in signalling the relationship between and among clauses.

8. Recognise the rhetoritical forms of written discourse and their significance for interpretation.

9. Recognise the communicative functions of written texts, according to form and purposes.

10. Infer context that is not explicit by using background knowledge.

11. From events, ideas, etc., described, infer links and connections between events, deduce causes and effects, and detect such relations as main idea, supporting idea, new information, generalisation, and examplification.

12. Distinguish between literal and implied meanings.

13. Detect culturally specific references and interpret them in a context of the appropriate cultural schemata.
14. Develop and use battery of reading strategies, such as scanning and skimming, detecting discourse markers, guessing the meaning of words from context, and activating schemata for interpretation of texts.

Furthermore, it is suggested in the lists that reading comprehension abilities be closely related to writing abilities, especially when they involve comprehending the organisation of the text. In this case, the two primary language skills are mutually reinforcing.

\section{THE VARIABLES INVOLVED IN COMPREHENSION}

Shrum \& Glisan (1994:114-116) review some research findings on the variables involved in comprehension. According to them, there are six variables that affect comprehension, both oral and written. The first variable is the importance of context and background knowledge in understanding input. The degree to which the reader is able to merge input with previously acquired knowledge structures or schemata, determines how successful he or she will be in comprehending. This linking of new and existing knowledge helps the reader make sense of the text more quickly.

The second variable is the degree to which the reader uses strategies such as guessing in context. Prediction of fortcoming input is one characteristic of native readers' processing. Many studies support the claim that learners who interact with text through strategies such as predicting, skimming, scanning, and using background knowledge comprehend much better than those who fail to use these strategies. 
The third variable is the purpose for reading or the nature of the task. The type of task determines the kind os strategy required. Two kinds of reading strategies, extensive and intensive, involve different objectives and skills. Extensive reading, usually reading for pleasure, requires the ability to understand main ideas, find specific information, and read quickly. Intensive reading, on the other hand, most often as reading for information, requires the ability to read for details, understanding implication, and follow relationships of thought throughout the text.

The fourth variable relates to the length of text presented for comprehension. At he beginning level, students are typically given shorter, edited texts to read. Students who process shorter texts are more likely to use wordfor-word processing strategies since the demands on memory permit greater attention to detail. Some evidence suggests that larger texts may be easier for students to comprehend because they are more cohesive and interesting to students, although the texts require more top-down processing.

The fifth variable in the comprehension process is related to the type of written text presented. Traditionally, the difficulty of texts has been judged on the basis of the simplicity of grammatical structures and the familiarity of the vocabulary. This may be due to the fact that comprehension is tested on the basis of grammar and vocabulary recognition rather than on the interaction with the text's message. But empirical studies revealed that exposure to texts with unfamiliar grammar and vocabulary does not significantly affect comprehension. Other factors such as the quality of the text itself in terms of factual consistency and coherence, as well as the background knowledge and motivation of learners, may be more important considerations for teachers when selecting texts.

The sixth variable in comprehension is the treatment of new vocabulary. It is acknowledged that the use of vocabulary lists with definitions does little to help the reader build vocabulary or comprehend more effectively while reading. It will be more effective if new words are presented in their thematic and discourse relationship to the text than in their dictionary definitions. As an alternative, the teacher uses pre- and post-reading discussion in order to link text information to reader background knowledge.

Therefore, in order to comprehend written texts well, the instructor should take into consideration the following variables: (1) background knowledge of the student, (2) strategies that students use in the comprehension task, (3) purpose of reading or the nature of the task, (4) length of the text, (5) type of text, and (6) treatment of new vocabulary.

\section{CONCLUSION}

In the discussion the nature of reading, schema theory, reading comprehension, and the variables involved in reading comprehension has been reviewed. In discussing the nature of reading, the three models of reading namely Bottom-Up, Top-Down, and Interactive explained briefly. Then, The Schema Theory reinforces what has been discussed in The Nature of Reading Section. 
In reviewing reading comprehension, three points have been discussed: The History of Reading Instruction, Types and Purposes of Reading, and Cognitive Reading Skills. Finally, the variables in comprehension consists of (1) the importance of context and background knowledge in understanding input, (2) the degree to which the reader uses strategies in understanding the text, (3) the purpose for

\section{REFERENCES}

Carrel, P.L. \& Eisterhold, J.C. (1988). Schema theory and ESL Reading Pedagogy. In Patricia L. Carrel, et al. (Eds.). Interactive Approaches to Language Reading. Cambridge: Cambridge University Press.

Carrel, P.L. (1987). A View of Written Text as a Communicative Interaction: Implications for Reading in a Second Language. In Joanne Devine, et al. (Eds.). Research in Reading in English as a Second Language. Cambridge: Cambridge University Press.

Clarke, M.A. \& Silberstein, S. (1979). Toward a Realization of Psycholinguistics Principles in the ESL Reading Class. In Ronald Mackay, et al. (eds.). Reading In a Second Language. Rowley, Massachusetts: Newbury House Publisher, Inc.

Denies, L., McKenna, M.C. \& Miller, J.W. (1989). Project READ:s: Effective Design for Content Area Reading. Journal of Reading, 22(6).

Goodman, K.H. (1967). Reading: A Psycholinguistic Guessing Game. Journal of the Reading Specialist, 6, 126-35. reading or the nature of the task, (4) the length of text presented for comprehension, (5) the type of written text presented, and (6) how to treat the vocabulary.

The writer hopes this article would help those involved in the teaching of reading comprehension to widen the knowledge and understanding of as well as developing reading materials.

Greenwood, J. (1981). Comprehension and Reading. In Gerry Abbot, et al. (eds.) The Reading of English as an International Language: A Practical Guide. pp. 35-47. Glasgow: William Collins Sons and Co. Ltd.

Grellet, F. (1987) Developing Reading Skills. Cambridge: Cambridge University Press.

Harris, A. J. \& Sipay, E. R. (1984). How to Increase Reading Ability. Seventh Edition. New York: Longman

Lee, J.F. \& vanPatten, B. (1995). Making Communicative Language Teaching Happen. New York: McGraw-Hill, Inc.

Mueller, A.M. \& Tiffany, D.A. (n.d.). English as a Second Language, Secondary Scope and Sequence (912). Iowa City: Iowa Community School District.

Omaggio, A.C. (1986). Teaching Language in Context: Proficiency-Oriented Instruction. Boston, Massachusetts: Heinle \& Heinle Publisher, Inc.

Papalia, A. (1987). Interaction of reader and text. In Wilga M. Rivers. (Ed.). Interactive Language Teaching. Cambridge: Cambridge University Press. 
Rumelhart, D.E. (1980). Schemata: The Building Blocks of Cognition. In Rand J. Spiro, et al.(eds.) Theoretical Issues in Reading Comprehension. Hillsdale, N.J.: Lawrence Erlbaum Associates, Publishers.

Silberstein, S. (1987). Let's Take Another Aother Look at Reading: TwentyFive Years of Reading Instruction. English Teaching Form, 26(4), 28-35.
Smith, F. (1971). Understanding Reading: A Psycholinguistic Analysis of Reading and Learning to Read. New York: Holt, Rinehart and Winston, Inc.

Smith, F. (1973). Psycholinguistics and Reading. New York: Holt, Rinehart and Winston, Inc. 
